PENGARUH KEDALAMAN MUKA AIR TANAH TERHADAP LILIT BATANG KARET

CLON PB260 DAN SIFAT KIMIA TANAH GAMBUT

DI KEBUN MERANTI RAPP RIAU

\title{
THE EFFECT OF WATER TABLE DEEP TO TRUNK CIRCUMFERENCE RUBBER PB260 CLON AND SOIL CHEMISTRY OF PEAT SOIL IN MERANTI ESTATE RAPP OF RIAU
}

\author{
Aries Sukariawan ${ }^{1}$, Abdul Rauf ${ }^{2 *}$, Arief Setiawan Sutanto ${ }^{1}$ dan Bolot Santoso ${ }^{1}$ \\ ${ }^{1}$ Sekolah Tinggi Ilmu Perkebunan Agribisnis Perkebunan (STIPAP), Medan- 20222 \\ ${ }^{2}$ Program Studi Agroteknologi, Fakultas Pertanian USU, Medan - 20155 \\ *Corresponding author : E-mail: a_rauf_soil@yahoo.com
}

\section{ABSTRACTS}

Study to evaluate the effect of the depth of water table in peatlands of the PB260 rubber girth immature plants (age 2-3 years) and chemical properties of peat soil has been carried out in Meranti Estate RAPP Kampar Estuary Pangkalan Kerinci District of Riau in December 2013. Research used descriptive method with measuring water table depth in selected plots with girth measurements of planting rubber trees planted in 2010 and 2011. At two sample plots (representing the shallowest water level and water level deep) dug each soil profile to the investigation and decision soil samples. Soil samples were analyzed at the Laboratory of BPTP North Sumatra. The results showed that the water table in peatlands deeper, reaching $88.6 \mathrm{~cm}$ girth will decrease the growth of young rubber trees. Rubber immature plants age 2 years who has the best girth growth in ground water at a depth of $29.6 \mathrm{~cm}$ deep and 3 years old trunk circumference rubber girth best growth at $65.3 \mathrm{~cm}$ water table. Water table is within reach mean $88.6 \mathrm{~cm}$ cause faster decomposition of peat soil is characterized by $C / N$ ratio of lower and lower quality (fertility) peat soils with lower ash content, $K$-exchangeable, Mg-exchangeable, $P$-available and $P$-total.

Keywords: peat soil water table, trunk circumference rubber, chemical properties of soil.

\section{ABSTRAK}

Penelitian untuk mengevaluasi pengaruh kedalaman muka air tanah pada lahan gambut terhadap lilit batang karet PB260 TBM (umur 2-3 tahun) dan sifat kimia tanah gambut telah dilakukan di Kebun Meranti RAPP Muara Kampar Kabupaten Pangkalan Kerinci Riau pada Desember 2013. Penelitian menggunakan metoda deskriptif dengan jalan melakukan pengukuran kedalaman muka air tanah di petak terpilih disertai pengukuran lilit batang tanaman karet tahun tanam 2010 dan tahun tanam 2011. Pada dua petak sampel (mewakili muka air terdangkal dan muka air terdalam) digali masing-masing satu lubang profil tanah guna penyidikan dan pengambilan sampel tanah. Sampel tanah dianalisis di Laboratorium BPTP Sumatera Utara. Hasil penelitian menunjukkan bahwa muka air tanah di lahan gambut yang semakin dalam, mencapai 88,6 cm akan menurunkan pertumbuhan lilit batang tanaman karet muda (TBM). Karet TBM umur 2 tahun yang memiliki pertumbuhan lilit batang terbaik pada kedalaman muka air tanah sedalam 29,6 cm dan karet TBM umur 3 tahun pertumbuhan lilit batang terbaik pada muka air tanah 65,3 cm. Muka air tanah yang dalam mencapai rerata 88,6 cm menyebabkan dekomposisi gambut lebih cepat ditandai dengan rasio $C / N$ yang lebih rendah dan menurunkan kualitas (kesuburan) tanah gambutnya dengan turunnya kadar abu, $K$-dd, $M g$-dd, P-tersedia dan P-total tanah.

Kata kunci: muka air tanah gambut, lilit batang karet, sifat kimia tanah. 


\section{PENDAHULUAN}

Pengelolaan air (water management) merupakan faktor penentu keberhasilan dalam melakukan budidaya tanaman pertanian, perkebunan dan bahkan untuk budidaya tanaman hutan (silvikultur) di lahan gambut. Berbeda dengan tanah mineral, bahan aktif tanah di lahan/tanah gambut adalah air gambut itu sendiri. Di dalam air gambut larut asam-asam organik yang berfungsi sebagai koloid tanah gambut (tempat terjadinya pertukaran ion), selain larut pula unsur-unsur hara dan zat pengatur tumbuh lainnya. Itu sebabnya, pembuatan parit drainase di lahan gambut bukan dimaksudkan untuk membuang air yang selalu menggenang di lahan gambut, namun lebih ditujukan untuk menurunkan muka air di bawah permukaan tanah gambutnya hingga kedalaman yang sesuai dengan kebutuhan tanaman dan kebutuhan pelestarian tanah gambut itu sendiri.

Keberadaan air gambut yang harus dipertahankan, selain harus sesuai dengan kebutuhan tanaman yang akan dibudidayakan, juga untuk mencegah degradasi gambut dan menekan terjadinya emisi gas rumah kaca (GRK). Kebutuhan tanaman akan air di tanah gambut, terutama tanaman lahan kering didasarkan kepada kadar air kapasitas lapang. Kadar air kapasitas lapang untuk gambut umumnya setara dengan $300 \%$. Kadar air tanah gambut yang kurang dari $300 \%$ (mencapai sekitar $273 \%$ ) sudah tergolong ke dalam kadar air kritis (kadar air titik layu permanen) yang menyebabkan tanaman layu/mati. Kondisi kadar air kritis juga akan memicu terjadinya degradasi gambut yang diawali dengan terbentuknya pseudosand (pasir semu) yang bersifat irreversible drying (kering tak balik). Degradasi gambut akan berlanjut dengan terjadinya subsidensi (penurunan muka tanah) bila air gambut selalu dalam kondisi kadar air kritis dan muka air gambut yang terlalu dalam.

Terjadinya kadar air kritis pada tanah gambut dapat diakibatkan oleh beberapa faktor diantaranya: (a) iklim/musim kemarau yang panjang, (b) kebakaran lahan gambut, (c) pembukaan lahan dengan mengupas/mengolah tanah, (d) sistem parit dan pembuatan drainase yang kurang baik. Kombinasi faktorfaktor tersebut, yaitu pembukaan lahan gambut dengan cara membakar serasah dan mengupas/mengolah tanah menggunakan alat berat, disertai pembuatan parit drainase yang terlalu dalam dan dilakukan pada musim kemarau panjang akan lebih memperparah terjadinya degradasi gambut, berupa subsidensi, irreversible drying, dan emisi gas rumah kaca yang tinggi.

Pembukaan lahan gambut yang dapat menjaga kelestarian gambut, atau sekurang-kurangnya menekan laju degradasi lahannya, sekaligus dapat mendukung pertumbuhan tanaman dengan baik, persyaratan utamanya adalah dengan melakukan pengelolaan air (water management) yang baik. Pengelolaan air pada lahan gambut yang baik diawali dengan pembukaan lahan dengan tanpa olah tanah (TOT) atau tidak melakukan pengupasan/pengolahan tanah gambut dengan alat berat dengan pembuatan parit drainase berdasarkan konsep penurunan muka air gambut ke level yang masih mendukung terciptanya kadar air kapasitas lapang tanah gambut di bagian permukaan. Kedalaman muka air yang ideal untuk tujuan tersebut adalah $20 \mathrm{~cm}$ (bisa hingga maksimum $30 \mathrm{~cm}$ ) untuk tanaman semusim dan sekitar $60 \mathrm{~cm}$ (bisa hingga maksimum $100 \mathrm{~cm}$ ) untuk tanaman tahunan (tanaman keras). Pemanfaatan lahan gambut untuk tanaman tahunan (perkebunan, tanaman industri, hutan tanaman dan atau buah-buahan) dengan 
kedalaman muka air yang cukup dalam itu $(60-100 \mathrm{~cm})$ harus menyertakan penutupan muka tanah menggunakan cover crop (tanaman penutup tanah) atau membiarkan rerumputan dan gulma tumbuh di lahan sela tanaman tahunan tersebut. Keberadaan tanaman penutup tanah tersebut juga sangat membantu menekan terjadinya emisi gas rumah kaca, selain menekan evapotranspirasi.

\section{BAHAN DAN METODE}

Penelitian dilakukan pada Desember 2013 di Kebun Meranti Riau Andalan Pulp and Paper (RAPP) Kabupaten Pangkalan Kerinci Riau. Penelitian menggunakan metoda deskriptif dengan jalan melakukan pengukuran kedalaman muka air tanah di petak terpilih disertai pengukuran lilit batang tanaman karet tahun tanaman 2010 dan tahun tanam 2011. Lokasi sampel untuk tahun tanam 2010 adalah di petak B744 dan B751, sedangkan untuk sampel tahun tanam 2011 di ambil dari petak D835. Sampel untuk pengukuran lilit batang dilakukan sebanyak 10 tanaman untuk masingmasing petak disertai dengan pengukuran kedalaman muka air tanahnya masing-masing.

Tabel 1. Rataan kedalaman muka air tanah terhadap rataan lilit batang karet PB260 di lahan gambut Kebun Meranti RAPP Riau.

\begin{tabular}{ccc}
\hline Kedalaman Muka Air Tanah $(\mathrm{Cm})$ & Lilit Batang $(\mathrm{Cm})$ & Tahun Tanam \\
\hline 88,6 & 12,30 & 2010 \\
65,3 & 27,05 & 2010 \\
29,6 & 16,40 & 2011 \\
\hline
\end{tabular}

Sumber: Data primer diukur setinggi dada pada pengamatan tanggal 19 Desember 2013.

Dari Tabel 1 dapat diketahui bahwa semakin dalam kedalaman muka air tanah semakin kecil rataan lilit batang yang dihasilkan karet muda (berumur 2-3 tahun) atau tanaman karet belum menghasilkan (TBM). Rataan kedalaman muka air tanah mencapai $88,6 \mathrm{~cm}$ justru menghasilkan lilit batang terendah $(12,30 \mathrm{~cm})$ pada karet umur 3 tahun, meskipun dibandingkan pada karet yang ditanaman 2011 (umur 2
Pada dua petak sampel (mewakili muka air terdangkal dan muka air terdalam) digali masing-masing satu lubang profil tanah guna penyidikan dan pengambilan sampel tanah di dua lapisan yaitu 0-20 $\mathrm{cm}$ dan 40-60 cm. Sampel tanah dianalisis di Laboratorium BPTP Sumatera Utara di Medan untuk mendapatkan data tentang nilai Kapasitas Tukar Kation (KTK), kadar C-organik, N-total, rasio $\mathrm{C} / \mathrm{N}, \mathrm{P}$ tersedia, P-total, K-dapat dipertukarkan, dan Mg-dapat dipertukarkan, serta kadar abu gambut. Penilaian sifat kimia dan hara tanah dilakukan secara kualitatif berdasarkan kriteria sifat kimia tanah yang dikeluarkan oleh BPT Bogor (2005).

\section{HASIL DAN PEMBAHASAN}

\section{Pengaruh Muka Air Tanah Terhadap Lilit Batang Karet}

Pengaruh kedalaman muka air tanah terhadap lilit batang karet PB260 setinggi dada yang ditanam di lahan gambut Kebun Meranti Riau Andalan Pulp and Paper (RAPP) Desa Meranti Muara Kampar Kabupaten Pangkalan Kerinci Riau disajikan pada Tabel 1. tahun) pada rataan kedalaman muka air tanah yang hanya $29,6 \mathrm{~cm}$ yang menghasilkan rataan lilit batang menjacapi $16,40 \mathrm{~cm}$ (1,3 kali lebih besar dibandingkan lilit batang karet umur 3 tahun yang ditanam pada rataan kedalaman muka air tanah 88,6 cm tersebut).

diketahui bahwa peningkatan kedalaman muka air tanah sebesar 35,7 
cm (dari 29,6 cm menjadi 65,3 cm) meningkatkan lilit batang sebesar 10,65 $\mathrm{cm}$ (dari $16,4 \mathrm{~cm}$ menjadi $27,05 \mathrm{~cm}$ ) sejalan dengan peningkatan umur tanaman dari umur 2 tahun (tahun tanam 2011) ke 3 tahun (tahun tanam 2010). Hal ini memberikan gambaran bahwa pengelolaan muka air tanah sangat penting dalam menghasilakan pertumbuhan karet di lahan gambut. Kedalaman muka air tanah sekitar 30 $\mathrm{cm}$ sangat baik bagi pertumbuhan tanaman karet umur 2 tahun dan ditingkatkan menjadi sekitar $65 \mathrm{~cm}$ pada umur tanam 3 tahun (dengan rataan lilit batang $27,05 \mathrm{~cm}$ ) dan terus dipertahankan pada kedalaman ini karena kedalaman yang semakin dalam mencapai $88-90 \mathrm{~cm}$ justru menurukan pertumbuhan karet di lahan gambut yang ditandai dengan rataan lilit batang yang lebih kecil $(12,3 \mathrm{~cm})$.

\section{Pengaruh Muka Air Tanah Terhadap Sifat Kimia Tanah Gambut}

Pengaruh muka air tanah terhadap sifat kimia tanah gambut yang ditanami karet di Kebun Meranti RAPP Riau disajikan pada Tabel 2. Dari Tabel 2 dapat diketahui bahwa lahan gambut dengan muka air lebih dalam $(88,6 \mathrm{~cm})$

Tabel 2. Hasil analisis bahan tanah gambut pada dua kedalaman muka air tanah di kebun karet, Kebun Meranti RAPP Riau.

\begin{tabular}{|c|c|c|c|c|c|}
\hline \multirow{2}{*}{ No. } & \multirow{2}{*}{$\begin{array}{l}\text { Parameter } \\
\text { Analisa*) }\end{array}$} & \multicolumn{2}{|c|}{$\begin{array}{c}\text { Kedalaman Muka Air Tanah } \\
29,6 \mathrm{Cm}\end{array}$} & \multicolumn{2}{|c|}{$\begin{array}{l}\text { Kedalaman Muka Air } \\
\text { Tanah } 88,6 \mathrm{Cm}\end{array}$} \\
\hline & & $\begin{array}{l}\text { Lap.Atas } \\
(0-20 \mathrm{Cm})\end{array}$ & $\begin{array}{l}\text { Lap.Bawah } \\
(40-60 \mathrm{Cm})\end{array}$ & $\begin{array}{l}\text { Lap.Atas } \\
(0-20 \mathrm{Cm})\end{array}$ & $\begin{array}{l}\text { Lap.Bawah } \\
(40-60 \mathrm{Cm})\end{array}$ \\
\hline 1 & C-organik (\%) & $\left.44,89(\mathrm{ST})^{* *}\right)$ & $65,40(\mathrm{ST})$ & $45,21(\mathrm{ST})$ & $50,89(\mathrm{ST})$ \\
\hline 2 & N-total $(\%)$ & $1,04(\mathrm{ST})$ & $0,98(\mathrm{ST})$ & $1,20(\mathrm{ST})$ & $1,28(\mathrm{ST})$ \\
\hline 3 & Rasio C/N & $43,16(\mathrm{ST})$ & 66,73 (ST) & $37,68(\mathrm{ST})$ & $39,78(\mathrm{ST})$ \\
\hline 4 & P-Bray-I (ppm) & $30,85(\mathrm{~T})$ & $26,88(\mathrm{~T})$ & $24,33(\mathrm{~S})$ & $30,28(\mathrm{~T})$ \\
\hline 5 & $\begin{array}{l}\mathrm{P}_{2} \mathrm{O}_{5} \text { total } \\
(\mathrm{mg} / 100 \mathrm{~g})\end{array}$ & $20,19(\mathrm{ST})$ & $15,76(\mathrm{ST})$ & $10,89(\mathrm{ST})$ & $9,25(\mathrm{ST})$ \\
\hline 6 & K-dd (me/100g) & $0,41(\mathrm{~S})$ & $0,16(\mathrm{R})$ & $0,11(\mathrm{R})$ & $0,15(\mathrm{R})$ \\
\hline 7 & Mg-dd (me/100g) & $1,63(\mathrm{~S})$ & $1,25(\mathrm{~S})$ & $1,22(\mathrm{~S})$ & $1,61(\mathrm{~S})$ \\
\hline 8 & KTK (me/100g) & $58,33(\mathrm{ST})$ & 64,91 (ST) & $59,25(\mathrm{ST})$ & $70,55(\mathrm{ST})$ \\
\hline 9 & $\mathrm{pH} . \mathrm{H}_{2} \mathrm{O}$ & $3,70(\mathrm{SM})$ & 3,97 (SM) & $3,35(\mathrm{SM})$ & $3,76(\mathrm{SM})$ \\
\hline 10 & Kadar Abu (\%) & 4,00 & 3,00 & 2,00 & 1,00 \\
\hline
\end{tabular}

Sumber: *)Data primer, sampel dianalisis di Laboratorium BPTP Sumatera Utara Ket.: **)ST = sangat tinggi; $\mathrm{T}=$ tinggi; $\mathrm{S}=$ sedang; $\mathrm{R}=$ rendah; $\mathrm{SM}=$ sangat masam tingkat dekomposisinya lebih tinggi, ditandai dengan rasio $\mathrm{C} / \mathrm{N}$ yang lebih rendah, baik pada lapisan atas maupun pada lapisan bawah, dibandingkan pada lahan gambut yang muka air tanah yang lebih dangkal. Sejalan dengan itu, kadar N-totalnya juga lebih tinggi, meskipun berdasarkan kriteria sifat kimia tanah yang dikeluarkan oleh Balai Penelitian Tanah Bogor (2005) semua kadar Ntotal yang terdapat pada semua kondisi lahan gambut tersebut tergolong sangat tinggi.

Tingkat dekomposisi yang lebih tinggi akan berakibat pada penurunan muka gambut (subsidensi) dan dapat menurunkan kualitas (kesuburan) gambut. Penurunan kualitas gambut tersebut ditandai dengan penurunan kadar abu, kadar K-tukar, kadar Mgtukar, kadar P, baik P-tersedia maupun P-total pada gambut dengan muka air tanah yang dalam $(88,6 \mathrm{~cm})$ dibandingkan tanah gambut yang muka air tanahnya lebih dangkal $(29,6 \mathrm{~cm})$ (Tabel 2). Kadar abu mengindikasikan tingkat kesuburan gambut. Semakin tinggi kadar abu dari suatu gambut menandakan gambut tersebut lebih subur. 


\section{SIMPULAN DAN SARAN}

\section{Simpulan}

Muka air tanah di lahan gambut yang semakin dalam, mencapai $88,6 \mathrm{~cm}$ akan menurunkan pertumbuhan lilit batang tanaman karet muda (TBM). Karet TBM umur 2 tahun yang ditanam di lahan gambut memiliki pertumbuhan lilit batang terbaik pada kedalaman muka air tanah sedalam 29,6 cm dan karet TBM umur 3 tahun pertumbuhan lilit batang terbaik pada muka air tanah $65,3 \mathrm{~cm}$. Muka air tanah yang dalam mencapai rerata $88,6 \mathrm{~cm}$ menyebabkan dekomposisi gambut lebih cepat ditandai dengan rasio $\mathrm{C} / \mathrm{N}$ yang menjadi lebih rendah dan menurunkan kualitas (kesuburan) tanah gambutnya dengan turunnya kadar abu, K-dd, Mg-dd, Ptersedia dan P-total.

\section{Saran}

Pengelolaan air pada lahan gambut yang dibuka untuk budidaya karet tergantung pada umur tanaman. Pada umur sampai 2 tahun sebaiknya dipertahankan muka air tanah sedalam maksimum $30 \mathrm{~cm}$ dan pada umur 3 tahun dan seterusnya dipertahankan pada kedalaman $65 \mathrm{~cm}$.

\section{DAFTAR PUSTAKA}

Agus, F. dan I G.M. Subiksa. 2008. Lahan Gambut: Potensi Untuk Pertanian Dan Aspek Lingkungan. Balai Penelitian Tanah. Bogor.

Balai Penelitian Tanah. 2003. Petunjuk Teknis Evaluasi Lahan Untuk Komoditas Pertanian. Pusat Penelitian dan Pengembangan Tanah dan Agroklimat, Badan Litbang Pertanian, Departemen Pertanian, Bogor.

Balai Penelitian Tanah. 2005. Petunjuk Teknis Analisa Kimia Tanah,
Tanaman, Air Dan Pupuk. Badan Penelitian dan Pengembangan

Pertanian, Departemen Pertanian, Bogor.

Barchia, M.F. 2012. Gambut; Agroekosistem dan Tranformasi Karbon. Gadjah Mada University Press.

Firmansyah, M. A., W. A. Nugroho dan M.S. Mokhtar. 2012. Pengelolaan Lahan Gambut Berkelanjutan: Studi Kasus Pengembangan Karet dan Tanaman Sela di Desa Jabiren Kabupaten Pulang Pisau Kalimantan Tengah. Balai Pengkajian Teknologi Pertanian Palangkaraya, Kalimantan Tengah.

N. Yuliani, W.A. Nugroho, A. Bhermana. 2012. Kesesuaian Lahan Rawa Pasang Surut untuk Tanaman Karet di Tiga Desa Eks Lahan Sejuta Hektar, Kabupaten Pulang Pisau, Provinsi Kalimantan Tengah. Jurnal Lahan Suboptimal ISSN: 2252-6188 (Print), ISSN: 23023015 (Online) Vol. 1, No.2: 149157, Oktober 2012.

Rauf, A., dan Rahmawaty. 2013. Kajian Potensi Lahan Gambut di Pantai Timur Sumatera Utara untuk Pertanian. Dinas Pertanian Sumatera Utara.

Widyati, E. 2012. Kajian Optimasi Pengelolaan Lahan Gambut dan Isu Perubahan Iklim. Pusat Litbang Konservasi dan Rehabilitasi Lahan, Bogor. 